\title{
Roles of XB130, a novel adaptor protein, in cancer
}

\author{
Atsushi Shiozaki ${ }^{\text {** }}$ Mingyao Liu' 2,3
}

\begin{abstract}
Adaptor proteins, with multi-modular structures, can participate in the regulation of various cellular functions. During molecular cloning process of actin filament associated protein, we have discovered a novel adaptor protein, referred to as XB130. The human xb130 gene is localized on chromosome 10q25.3, and encodes an 818 amino acid protein. The N-terminal region of XB130 includes several tyrosine phosphorylation sites and a proline-rich sequence that might interact with Src homology 2 and 3 domain-containing proteins, respectively. Our studies have indeed implicated XB130 as a likely substrate and regulator of tyrosine kinase-mediated signaling. Down-regulation of endogenous XB130 with small interfering RNA reduced C-Src activity, IL-8 production and phosphorylation of Akt in human lung epithelial cells. Further, XB130 binds the p85a subunit of phosphatidyl-inositol-3-kinase and subsequently mediates signaling through RET/PTC in thyroid cancer cells. Knockdown of XB130 using small interfering RNA inhibited $\mathrm{G}_{1}-\mathrm{S}$ phase progression, induced spontaneous apoptosis and enhanced intrinsic and extrinsic apoptotic stimulus-induced cell death in human lung and thyroid cancer cells. Growth of tumors in nude mice formed from XB130 short hairpin RNA stably transfected human thyroid cancer cells were significantly reduced, with decreased cell proliferation and increased apoptosis. Further, XB130 has a high affinity to lamellipodial F-actin meshwork and is involved in the motility and invasiveness of cancer cells. Gene expression profiling identified 246 genes significantly changed in XB130 short hairpin RNA transfected thyroid cancer cells. Among them, 57 genes are related to cell proliferation or survival, including many transcription regulators. Pathway analysis showed that the top ranked disease related to XB130 is Cancer, and the top molecular and cellular functions are Cellular Growth and Proliferation, and Cell Cycle. These observations suggest that the expression of XB130 may affect cell proliferation, survival, motility and invasion in various cancer cells. A deeper understanding of these mechanisms may lead to the discovery of XB130 as an important mediator in tumor development and as a novel therapeutic target for cancer.
\end{abstract}

\section{Review}

\section{Introduction}

Adaptor proteins are molecules of modular structures without enzymatic activity, composed of multiple protein-protein and/or protein-lipid interacting domains, through which they link signaling components to form macromolecular complexes and propagate cellular signals $[1,2]$. Depending on the functional role of the interacting partner and the specific biological event that is triggered by these interactions, adaptor proteins can participate in the regulation of different signaling pathways. A good example of how adaptor proteins are involved in signal transduction is the activation of c-Src protein-tyrosine kinases by adaptor proteins via protein-protein interactions. Adaptor proteins are also important to mediate

\footnotetext{
* Correspondence: shiozaki@koto.kpu-m.ac.jp

'Division of Digestive Surgery, Department of Surgery, Kyoto Prefectural

University of Medicine, Kyoto, 602-8566, Japan

Full list of author information is available at the end of the article
}

signals initiated via receptor-tyrosine kinases in responses to extracellular stimuli $[3,4]$, and together with nonreceptor protein-tyrosine kinases to orchestrate the signal transduction elicited by either ligand receptor interactions or by cellular structure reorganization [5]. Further, a number of adaptor proteins have been demonstrated to regulate tumorigenesis. For example, actin filament associated protein (AFAP) is required for actin stress fiber formation and cell adhesion, and is critical for tumorigenic growth in prostate cancer [6,7]. Tyrosine kinase substrate 5 is a scaffolding adaptor protein with five Src homology ( $\mathrm{SH}) 3$ domains, co-localizes to podosomes and regulates migration and invasion of different human cancer cells $[8,9]$. These findings support a broader investigation of adaptor proteins on tumorigenesis and their potentiality as diagnostic biomarkers and therapeutic targets of cancer.

During our studies aimed at the characterization of the AFAP [10-12], we cloned a novel $130 \mathrm{kDa}$ protein,
C Biomed Central

(c) 2011 Shiozaki and Liu; licensee BioMed Central Ltd. This is an Open Access article distributed under the terms of the Creative Commons Attribution License (http://creativecommons.org/licenses/by/2.0), which permits unrestricted use, distribution, and reproduction in any medium, provided the original work is properly cited. 
referred to as XB130 [13]. Our studies have indeed indicated that XB130 plays, as an adaptor, important roles in the regulation of signal transduction, cell proliferation, survival, motility and invasion [13-16]. In this review, we focus on studies relate to both XB130 and cancer progression.

\section{Molecular structure of XB130}

The human $x b 130$ gene is localized on chromosome $10 q 25.3$ and encodes 818 amino acids with an apparent molecular size of approximately $130 \mathrm{kDa}$ [13]. As an adaptor protein, the overall structure of XB130 shares similarity with AFAP, thus it is also known as actin filament associated protein 1-like 2 (AFAP1L2). The $\mathrm{N}$-terminal region of XB130 includes several tyrosine phosphorylation sites and a proline-rich sequence which can potentially interact with $\mathrm{SH} 2$ and $\mathrm{SH} 3$ domaincontaining proteins, respectively (Figure 1) [13,14]. The middle portion harbors two pleckstrin-homology $(\mathrm{PH})$ domains that may target proteins to cellular membranes through interactions with specific phospholipids, such as phosphoatidylinositol-3, 4, 5-triphosphate. The C-terminal region contains a coiled-coil domain, which might be involved in protein oligomerization and DNA binding. A common feature of XB130 and AFAP is the presence of a proline-rich motif, several potential $\mathrm{SH} 2$ binding sites and two PH domains (Figure 1) [13,14]. A coiled-coil domain of XB130 shares partial similarity with the leucine zipper domain in AFAP. Despite these similarities, XB130 does not behave like an actin filament-associated protein. The actin-binding site that is present in the $C$ terminus of AFAP [17] is only partially present in XB130. The distribution of AFAP appears to be along the stress fiber, and through its interaction, AFAP transmits physical force and mediates mechanical stretch-induced c-Src activation [12,18]. On the other hand, the diffuse distribution of XB130 in the cytoplasm suggests that XB130 plays a different role in signal transduction and cellular functions [13]. XB130's tissue distribution was determined by using northern blot analysis and high expression of XB130 was found in human thyroid and spleen [14].

\section{Regulation of tyrosine kinase-mediated signaling by XB130}

Our studies have implicated XB130 as a likely substrate and regulator of tyrosine kinase-mediated signaling $[13,14]$. Endogenous XB130 interacts with c-Src tyrosine kinase [13]. Their co-expression in COS-7 cells resulted in activation of c-Src and elevated tyrosine phosphorylation of multiple proteins, including XB130 itself. XB130 expression in HEK293 cells enhanced serum response element- and AP-1-dependent transcriptional activation mediated by c-Src. Down-regulation of endogenous XB130 with small interfering RNA (siRNA) reduced cSrc activity, IL-8 production, epidermal growth factor (EGF)-induced phosphorylation of Akt and GSK3 $\beta$ in human lung cancer A549 cells [13].

Further, our studies revealed expression of XB130 in human thyroid tissue, and we found that XB130 is a downstream mediator of the signaling cascade propagated by RET/PTC, a genetically rearranged, constitutively active, thyroid cancer-specific tyrosine kinase [14]. RET/PTC plays a pathogenic role and exhibits transforming ability by exerting its effects on differentiation, mitogenic and metastatic potential in papillary thyroid cancer $[19,20]$. XB130 couples RET/PTC signaling to the phosphatidyl-inositol-3-kinase (PI3K)/Akt signaling through a specific binding site to $\mathrm{p} 85 \alpha$ subunit of PI3K [14]. A study investigating the implications of Src

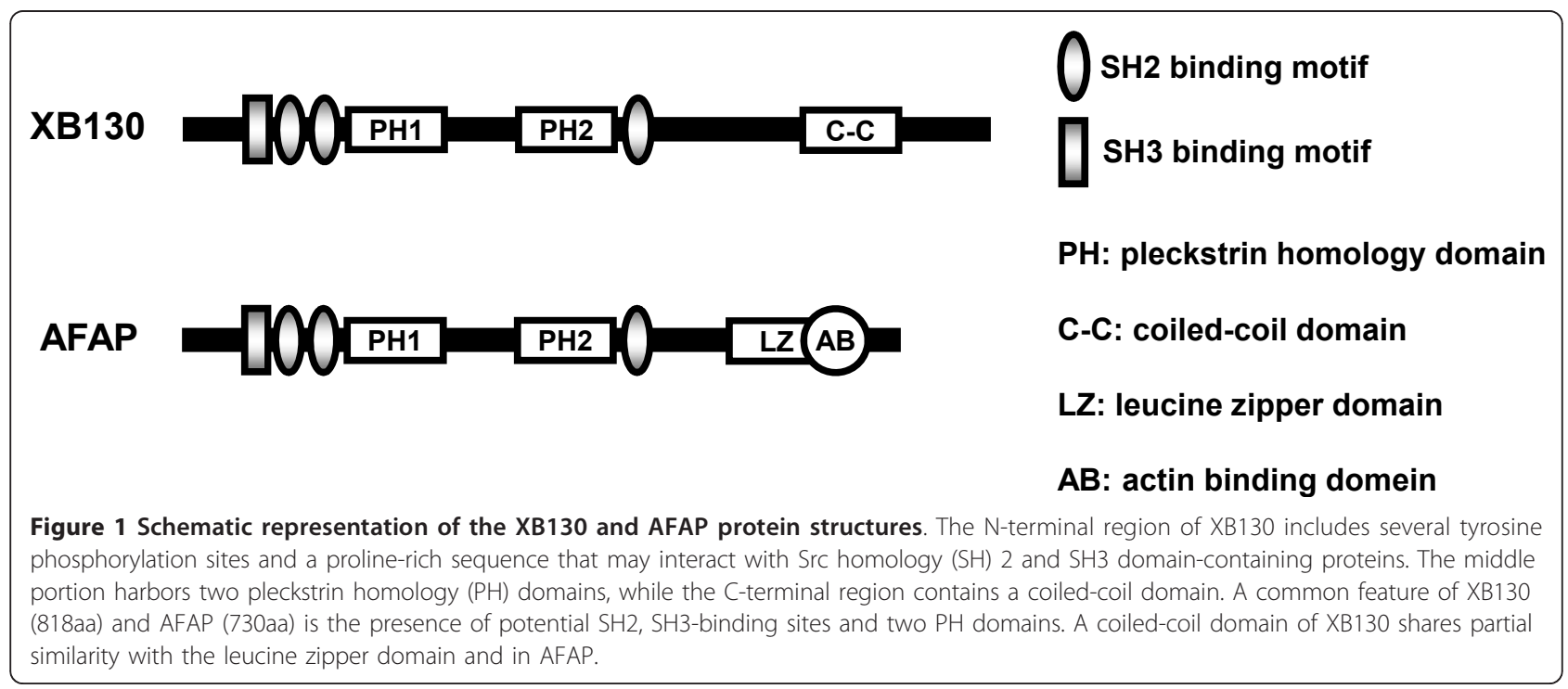


tyrosine kinases in certain colorectal cancer by Emaduddin et al. identified XB130 from SW629 colorectal cancer cells, as one of the tyrosine phosphorylated proteins binding to Lck-SH2 domain [21]. Lck, is a Src family member that is not detectable in normal colonic epithelium, but becomes aberrantly expressed in a subset of colorectal carcinomas. These findings indicate that $\mathrm{XB130}$ has an important role in the regulation of tyrosine kinase-mediated signaling.

Roles of XB130 in cell cycle and survival

To investigate the role of XB130 in cancer cell cycle progression, we conducted knockdown experiments with
XB130 siRNA [13-15]. Down regulation of XB130 reduced cell cycle progression from $G_{1}$ to $S$ phase in human lung cancer cell line, A549 and human thyroid cancer cell lines, TPC1 and WRO (Figure 2) [13-15]. The expression of cell proliferation markers, Ki-67 and PCNA, were also reduced in XB130 siRNA treated WRO cells [15]. Down-regulation of XB130 induced apoptosis and enhanced extrinsic or intrinsic apoptotic stimulus-induced early and late apoptosis in WRO cells (Figure 2) [15]. In TPC1 cells, down-regulation of XB130 accelerates the apoptotic process [14]. Further, to determine the roles of XB130 in vivo, we established XB130 short hairpin RNA (shRNA) stably transfected WRO cell lines and used a xenograft model in nude

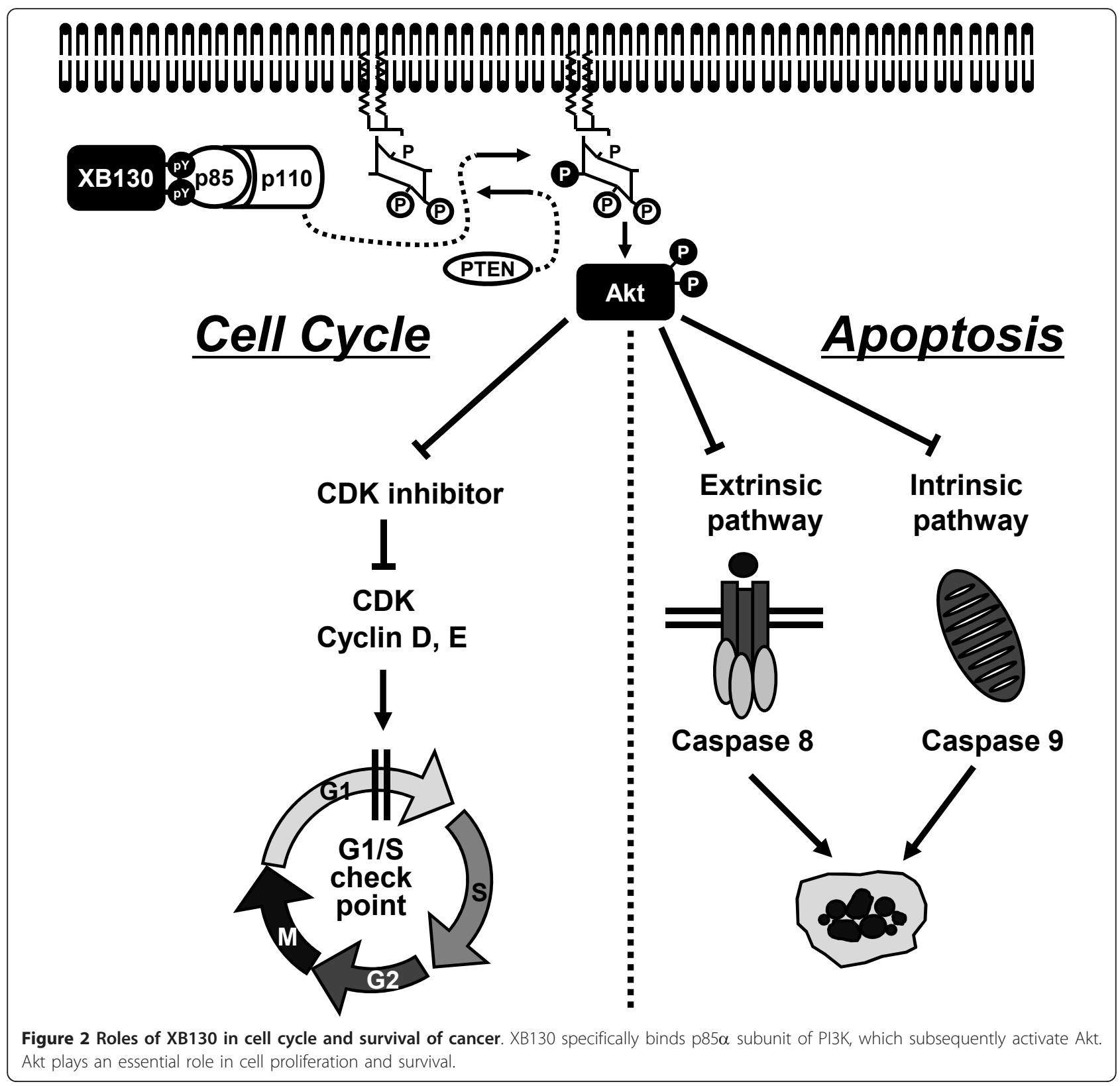


mice [15]. Growth of tumors in nude mice formed from XB130 shRNA stably transfected WRO cells were significantly reduced, with decreased cell proliferation and increased apoptosis. These findings indicate that XB130 expression levels affected cell proliferation and survival in cancer cells (Figure 2).

\section{Roles of XB130 in cell motility and invasion}

We further found that XB130 has a high affinity to lamellipodial F-actin meshwork and is involved in the motility and invasiveness of tumor cells. XB130 exhibited robust translocation to the cell periphery in response to various stimuli (including EGF, wounding and expression of constitutively active Rac) that elicit lamellipodium formation [16]. Structure-function analysis revealed that both the XB130 $\mathrm{N}$-terminus and $\mathrm{C}$-terminus harbor critical regions for its translocation to lamellipodia [16]. In TPC1 thyroid papillary carcinoma cells, silencing endogenous XB130 decreased the rate of wound closure, inhibited cell invasion through Matrigel, reduced lamellipodial persistence and slowed down spreading [16]. Thus, XB130 is a novel Rac/ cytoskeleton-regulated and cytoskeleton-regulating adaptor protein, which exhibits high affinity to lamellipodial F-actin and impacts motility and invasiveness of tumor cells.

Gene expression profile in XB130 shRNA transfected cells To determine the molecular mechanisms by which XB130 regulates cellular functions, we analyzed gene expression profiles in XB130 shRNA transfected cells by microarray and bioinformatics studies [15]. Microarray analysis identified 246 genes significantly changed in XB130 shRNA transfected cells. Among them, 57 genes, such as HSPA1A, BHLHE40, TOB1, DDIT3, SLC7A11 and $\mathrm{MYC}$ are related to cell proliferation or survival, including many transcription regulators. Ingenuity Pathway Analysis showed that the top ranked disease related to XB130 is Cancer, and the top molecular and cellular functions are Cellular Growth and Proliferation, and Cell Cycle [15]. These results indicate that the expression level of XB130 influences genes related to cellular growth and proliferation, cell cycle, cell death and organismal survival. Furthermore, Cunha et al. performed gene expression profiling using 102 soft tissue tumor samples, and found XB130 as one of the genes highly related to local aggressiveness [22]. Therefore, in addition to thyroid cancer, XB130 may also play important roles in other neoplasms.

\section{Conclusions}

We have provided evidence that XB130 plays important roles in tumor progression by promoting cell proliferation, survival, motility and invasion in various cancer cells (Figure 3). XB130 has profound effects on expression of genes related to tumorigenesis. These findings suggest that XB130 could be a novel oncoprotein in cancer. A deeper understanding of these mechanisms

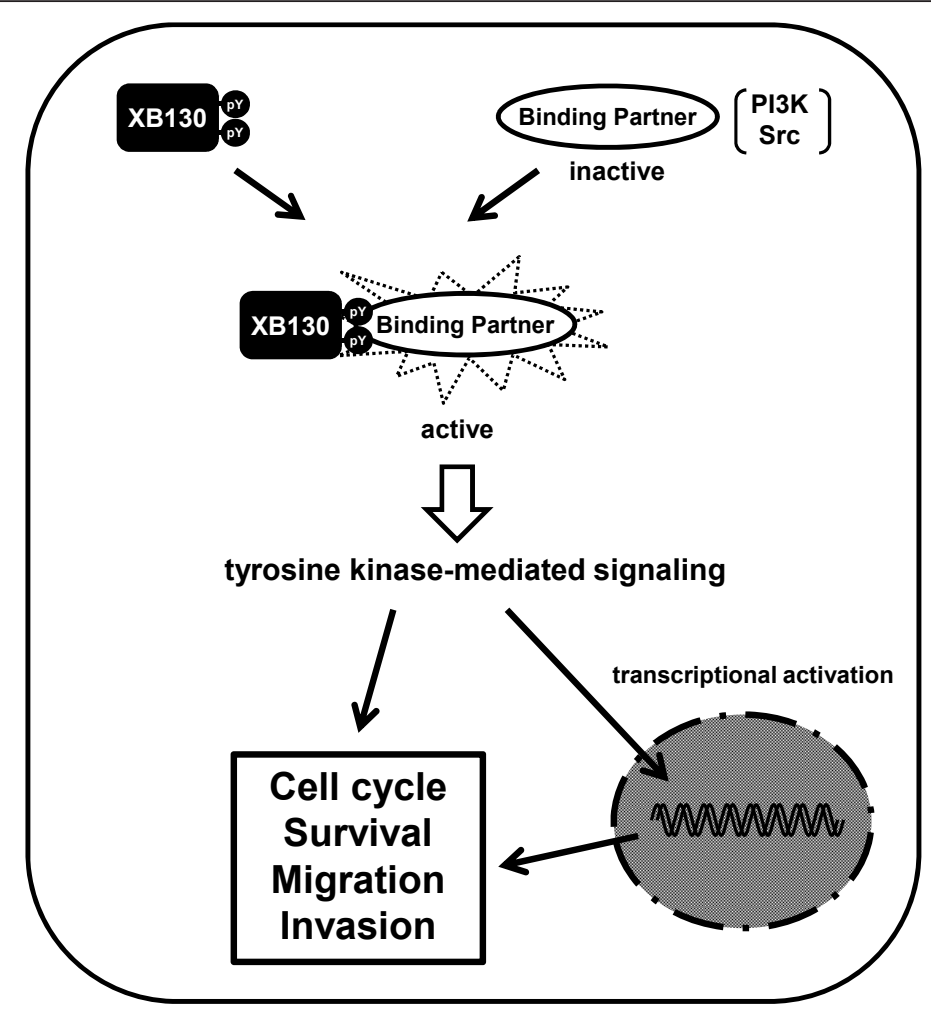

Figure 3 Roles of XB130 in cancer behavior. XB130 interacts with binding partners and regulates cell cycle, survival, migration and invasion of cancer through tyrosine kinase-mediated signaling. 
may lead to the discovery of XB130 as an important mediator in tumor development and as a novel therapeutic target for cancer.

\section{Acknowledgements}

Supported by operating grants (MOP-13270 and MOP-42546) from the Canadian Institutes of Health Research and by Research Fellowship Awards from Uehara Memorial Foundation and International Society of Heart and Lung Transplantation (AS).

\section{Lists of abbreviations}

AFAP: actin filament associated protein; AFAP1L2: actin filament associated protein 1-like 2; PH domain: pleckstrin-homology domain; PI3K: phosphatidyl-inositol-3-kinase; SH domain: Src homology domain; shRNA: short hairpin RNA; siRNA: small interfering RNA

\section{Author details}

'Division of Digestive Surgery, Department of Surgery, Kyoto Prefectural University of Medicine, Kyoto, 602-8566, Japan. ${ }^{2}$ Latner Thoracic Surgery Research Laboratories, University Health Network Toronto General Research Institute, Toronto, Ontario, M5G 1L7, Canada. ${ }^{3}$ Department of Surgery, Faculty of Medicine, University of Toronto, Toronto, Ontario, M5G 2C4, Canada.

\section{Authors' contributions}

AS carried out experiments concerning this review and wrote this manuscript. ML designed experiments and supervised research. All authors read and approved the final draft.

\section{Competing interests}

The authors declare that they have no competing interests.

Received: 11 November 2010 Accepted: 17 March 2011

Published: 17 March 2011

\section{References}

1. Flynn DC: Adaptor proteins. Oncogene 2001, 20:6270-6272.

2. Csiszar A: Structural and functional diversity of adaptor proteins involved in tyrosine kinase signalling. Bioessays 2006, 28:465-479.

3. Pawson $\mathrm{T}$ : Regulation and targets of receptor tyrosine kinases. Eur $J$ Cancer 2002, 38(Suppl 5):S3-S10.

4. Schlessinger J: New roles for Src kinases in control of cell survival and angiogenesis. Cell 2000, 100:293-296.

5. Tsygankov AY: Non-receptor protein tyrosine kinases. Front Biosci 2003, 8: s595-635.

6. Dorfleutner A, Stehlik C, Zhang J, Gallick GE, Flynn DC: AFAP-110 is required for actin stress fiber formation and cell adhesion in MDA-MB231 breast cancer cells. J Cell Physiol 2007, 213:740-749.

7. Zhang J, Park SI, Artime MC, Summy JM, Shah AN, Bomser JA Dorfleutner A, Flynn DC, Gallick GE: AFAP-110 is overexpressed in prostate cancer and contributes to tumorigenic growth by regulating focal contacts. J Clin Invest 2007, 117:2962-2973.

8. Seals DF, Azucena EF, Pass I, Tesfay L, Gordon R, Woodrow M, Resau JH, Courtneidge SA: The adaptor protein Tks5/Fish is required for podosome formation and function, and for the protease-driven invasion of cancer cells. Cancer Cell 2005, 7:155-165.

9. Blouw B, Seals DF, Pass I, Diaz B, Courtneidge SA: A role for the podosome/invadopodia scaffold protein Tks5 in tumor growth in vivo. Eur J Cell Biol 2008, 87:555-567.

10. Flynn DC, Leu TH, Reynolds AB, Parsons JT: Identification and sequence analysis of cDNAs encoding a 110-kilodalton actin filament-associated pp60src substrate. Mol Cell Biol 1993, 13:7892-7900.

11. Lodyga M, Bai XH, Mourgeon E, Han B, Keshavjee S, Liu M: Molecular cloning of actin filament-associated protein: a putative adaptor in stretch-induced Src activation. Am J Physiol Lung Cell Mol Physiol 2002, 283:L265-L274.

12. Han B, Bai XH, Lodyga M, Xu J, Yang BB, Keshavjee S, Post M, Liu M: Conversion of mechanical force into biochemical signaling. I Biol Chem 2004, 279:54793-54801.
13. Xu J, Bai XH, Lodyga M, Han B, Xiao H, Keshavjee S, Hu J, Zhang H, Yang BB, Liu M: XB130, a novel adaptor protein for signal transduction. J Biol Chem 2007, 282:16401-16412.

14. Lodyga M, De Falco V, Bai XH, Kapus A, Melillo RM, Santoro M, Liu M: XB130, a tissue-specific adaptor protein that couples the RET/PTC oncogenic kinase to PI 3-kinase pathway. Oncogene 2009, 28:937-949.

15. Shiozaki A, Lodyga M, Bai XH, Nadesalingam J, Oyaizu T, Winer D, Asa SL, Keshavjee S, Liu M: XB130, a novel adaptor protein, promotes thyroid tumor growth. Am J Pathol.

16. Lodyga M, Bai XH, Kapus A, Liu M: Novel adaptor protein XB130 is a Raccontrolled component of lamellipodia, which regulates cell motility and invasion. J Cell Sci

17. Qian Y, Baisden JM, Zot HG, Van Winkle WB, Flynn DC: The carboxy terminus of AFAP-110 modulates direct interactions with actin filaments and regulates its ability to alter actin filament integrity and induce lamellipodia formation. Exp Cell Res 2000, 255:102-113.

18. Han B, Lodyga M, Liu M: Ventilator-induced lung injury: role of proteinprotein interaction in mechanosensation. Proc Am Thorac Soc 2005, 2:181-187.

19. Grieco M, Santoro M, Berlingieri MT, Melillo RM, Donghi R, Bongarzone I, Pierotti MA, Della Porta G, Fusco A, Vecchio G: PTC is a novel rearranged form of the ret proto-oncogene and is frequently detected in vivo in human thyroid papillary carcinomas. Cell 1990, 60:557-563.

20. Kondo T, Ezzat S, Asa SL: Pathogenetic mechanisms in thyroid follicularcell neoplasia. Nat Rev Cancer 2006, 6:292-306.

21. Emaduddin M, Edelmann MJ, Kessler BM, Feller SM: Odin (ANKS1A) is a Src family kinase target in colorectal cancer cells. Cell Commun Signal 2008, 6:7.

22. Cunha IW, Carvalho KC, Martins WK, Marques SM, Muto NH, Falzoni R, Rocha RM, Aguiar S, Simoes AC, Fahham L, Neves EJ, Soares FA, Reis LF: Identification of genes associated with local aggressiveness and metastatic behavior in soft tissue tumors. Trans/ Oncol 2010, 3:23-32.

doi:10.1186/2043-9113-1-10

Cite this article as: Shiozaki and Liu: Roles of XB130, a novel adaptor protein, in cancer. Journal of Clinical Bioinformatics 2011 1:10.

\section{Submit your next manuscript to BioMed Central and take full advantage of:}

- Convenient online submission

- Thorough peer review

- No space constraints or color figure charges

- Immediate publication on acceptance

- Inclusion in PubMed, CAS, Scopus and Google Scholar

- Research which is freely available for redistribution

Submit your manuscript at www.biomedcentral.com/submit
C Biomed Central 